\title{
Design and Development of Variable Rate Spraying System Based on Canopy Volume Measurement
}

\author{
Kaiqun $\mathrm{Hu}^{1}$, Zetian $\mathrm{Fu}^{2}$, Ronghua $\mathrm{Ji}^{3}$, Jun Wang ${ }^{4}$, and Lijun $\mathrm{Qi}^{2, *}$ \\ ${ }^{1}$ College of Mechanical Engineering, Chongqing Technology and Business University, \\ Chongqing, 400067, P.R. China \\ ${ }^{2}$ College of Engineering, China Agriculture University, Beijing, 100083, P.R. China \\ qilijun@cau.edu.cn \\ ${ }^{3}$ College of electric and information engineering, China Agriculture University, \\ Beijing, 100083, P.R. China \\ ${ }^{4}$ Chinese Academy of Agricultural Mechanization Sciences, Beijing, 100083, P.R. China
}

\begin{abstract}
Variable rate spraying technology can improve the pesticide utilization ratio, reduce the waste of pesticide, and canopy volume was a very important variable rate reference in orchard spraying, so a variable rate spraying system based on canopy volume measurement was presented and developed. The system was mainly made up of PC, ultrasonic sensor, single chip, flow control mechanism and nozzles. Ultrasonic sensors were used to measure the distances between sensors and canopy foliage. Data detected by sensors were sent to computer by single chip for further processing. Flow control mechanisms were used to adjust the flow rates of nozzles real-timely. Hardware and software design were introduced. Hardware design included hardware choice, connections and installation positions designs, and software design included flow chart design and system operation interfaces designs which were used to display the measurement results real-timely and vividly, and some spraying controls of the system could be completed in the system operation interfaces.
\end{abstract}

Keywords: Variable rate spraying system, Canopy Volume measurement, Ultrasonic sensor, Single chip.

\section{Introduction}

Variable rate spraying technology could be divided into map-based and sensor-based variable rate technology by the information source of variable rate decision. Crop protection workers did many studies on variable rate spraying technology of mapbased. American MICRO-TRAK company developed the MT series automatic variables control system, the monitoring member surveyed the insect situation by the GPS antenna equipments mounted in the field. When insect situation was monitored, position of the disease insect area, type and density of the disease insects could be

\footnotetext{
Corresponding author.
} 
recorded and sent to the PC by the GPS , and the prescription map was built and imported to the corresponding GIS[1]. Baijing Qiu et al. developed a variables application control equipment of Automatic target detection based on GIS, whose work principle was as follow: information about the application prescription map was gained by GPS, the analysis and processing of real-time data and history data were completed by GIS, during application, the application instruction was built by the computer console based on GPS equipment orientation, speed information transmitted by radar sensors, circuit pressure and decision information[2,3]. Wanping Shi et al. analyzed the makeup and control technology of variable rate control system based on GPS and GIS[4]. Many studies were also done on the variable rate application technology based on sensor. Schumann et al. developed a measurement system of canopy volume, the Durand-Wayland ultrasonic ranging system[5] was used in their study[6]. Ritchie et al. measured the canopy height using an airborne laser altimeter[7]. Nilsson developed a system to measure tree height and canopy volume, which included an airborne lidar system[8]. Lei Tian et al. developed an "automatic weed control system in tomato field based on machine vision" and a "application system based on difference GPS" $[9,10,11]$. The variable rate application system could be divided into chemical injection control system and coordinate injection control system of chemical and water. Ess et al. of Purdue University presented the chemical injection control system. Rehfeld designed a constant-ratio and coaxial direct injection equipment[12]. Womac et al. designed a coordinate control system of chemical and water[13]. Yubo Guo et al. applied the static mixer into the direct injection variable rate spraying system[14]. Haiyan Zhou et al. presented a new variable ratio and rate injection spraying system[15].

A variable rate spraying system based on canopy volume measurement was developed, which used ultrasonic sensors to measure the tree canopy volume.

\section{Overall Design of Variable Rate Spraying System}

The orchard air-assisted sprayer Hardi LB-255 was fitted with ten ultrasonic sensors which were mounted on the mast fixed on the sprayer (five on each side of the mast) and two flow control mechanisms(one on each side of the machine) to modify the flow rate of the nozzles in real time. The ultrasonic sensors were used to detect the distances from the sensors to the foliage at the corresponding height. The canopy diameters of different heights would be computed by the distances detected by sensors, and then the canopy volumes could be calculated by the measurement method introduced by Kaiqun $\mathrm{Hu}[16]$. The single chips were used to send data from sensors to portable computer and transfer instructions from computer to flow control mechanisms in real time. Canopy volumes and canopy diameters measured by sensors were stored in the portable computer. The system was mainly made up of portable computer, single chips, ultrasonic sensors, flow control mechanisms and nozzle sets, and its schematic view is shown in Figure 1.

Where ultrasonic sensors L1-L5 and R1-R5 were mounted on the left and right side of the mast respectively, nozzles L1-L5 and R1-R5 were fixed on the left and right side of the sprayer respectively, flow control mechanism $\mathrm{L}$ and $\mathrm{R}$ were used to control the flow rates of Nozzles L1-L5 and Nozzles R1-R5 respectively. 
Sensors mounted on left and right side were numbered from L1 to L5 and R1 to R5 respectively, and were used to detect the trees on the left and right side of the sprayer respectively. In order to reduce the signal interferences between adjacent sensors, the sensors on each side of the mast were divided into two groups respectively: sensor 1 , 3,5 and sensor 2, 4, which worked by turns. Sensors on the left side were taken as an example to introduce the work detail of sensors and single chip, whose work schematic view is shown in Figure 2. The temperature wouldn't affect the measurement precision of the system obviously, so temperature compensation circuits of ultrasonic sensors were not designed in this system.

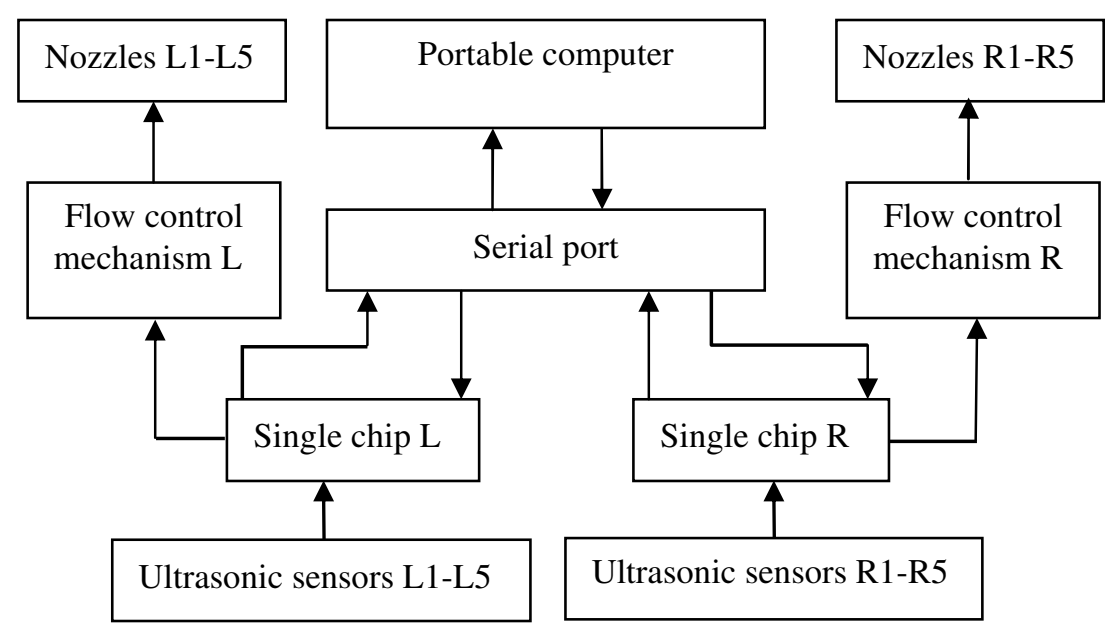

Fig. 1. Schematic view of variable rate spraying system based on canopy volume measurement

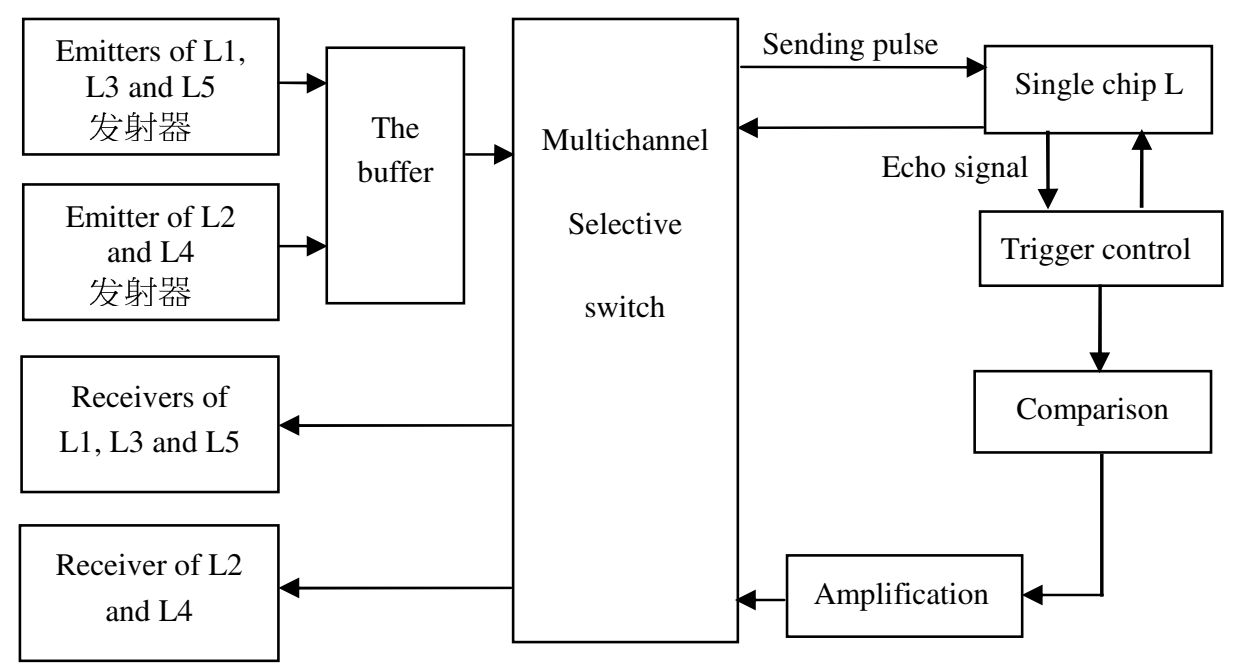

Fig. 2. Work schematic view of ultrasonic sensors and single chip 


\section{$3 \quad$ Hardware Design}

\subsection{Choice of Ultrasonic Sensor and Single Chip}

Ultrasonic distance measurement module DYP-ME007 produced by JieYue Science and Technology Ltd in Shen Zhen was used in this research, whose photograph is shown in Figure 3. Five pins were set in the sensor, which were VCC, Trig, Echo, Out and GND.

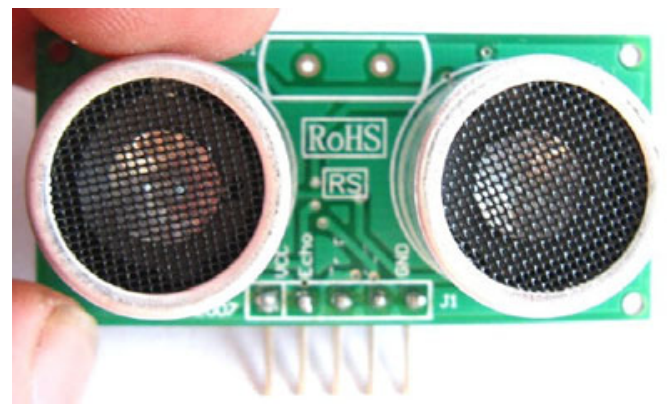

Fig. 3. Photograph of ultrasonic sensor

STC12C5A60S2 series single chip produced by Hong Jing Science and Technology Ltd was used in this research, which was a single clock/machine period single chip, and had characteristics of high speed, low power consumption and strong anti-interference. MAX810 special replacement circuit was integrated in the single chip. The photograph of single chip is shown in Figure 4.

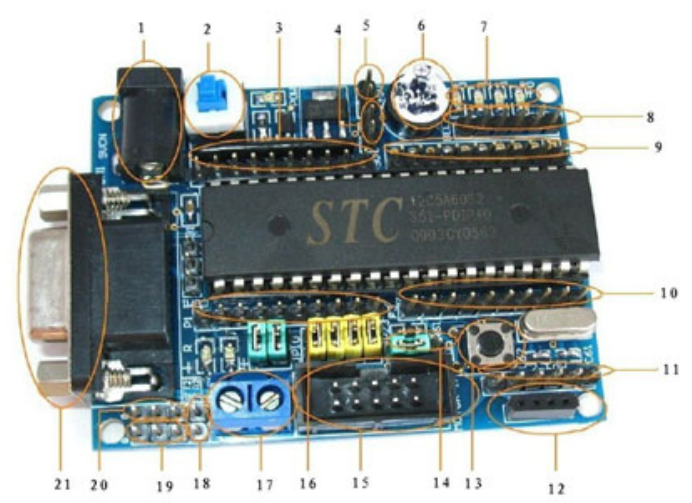

Fig. 4. The photograph of single chip

1 power plug 2 power switch $3 \mathrm{P} 0$ port 4 power contact pin $55 \mathrm{~V}$ power contact pin 6 buzzer 7 running light $8 \mathrm{AD}$ interface 1-4 $9 \mathrm{P} 2$ port $10 \mathrm{P} 3$ port $11 \mathrm{AD}$ import interface 5812 wireless module interface 13 replacement key-press 14 selection jumper of motor power 15 motor drive interface $16 \mathrm{P} 1$ port 17 heavy current terminal 18 power supply contact pin of motor power 19 COM2 interface 20 TTL power level of COM2 21 serial port head 


\subsection{Connection of Ultrasonic Sensor and Single Chip}

Four interfaces were needed by a ultrasonic sensor, VCC and GND were connected with VCC and GND of single chip, Trig and Echo were connected with the P port. Taking the left column sensors as an example, the connection of ultrasonic sensors and single chip is shown in Figure 5.

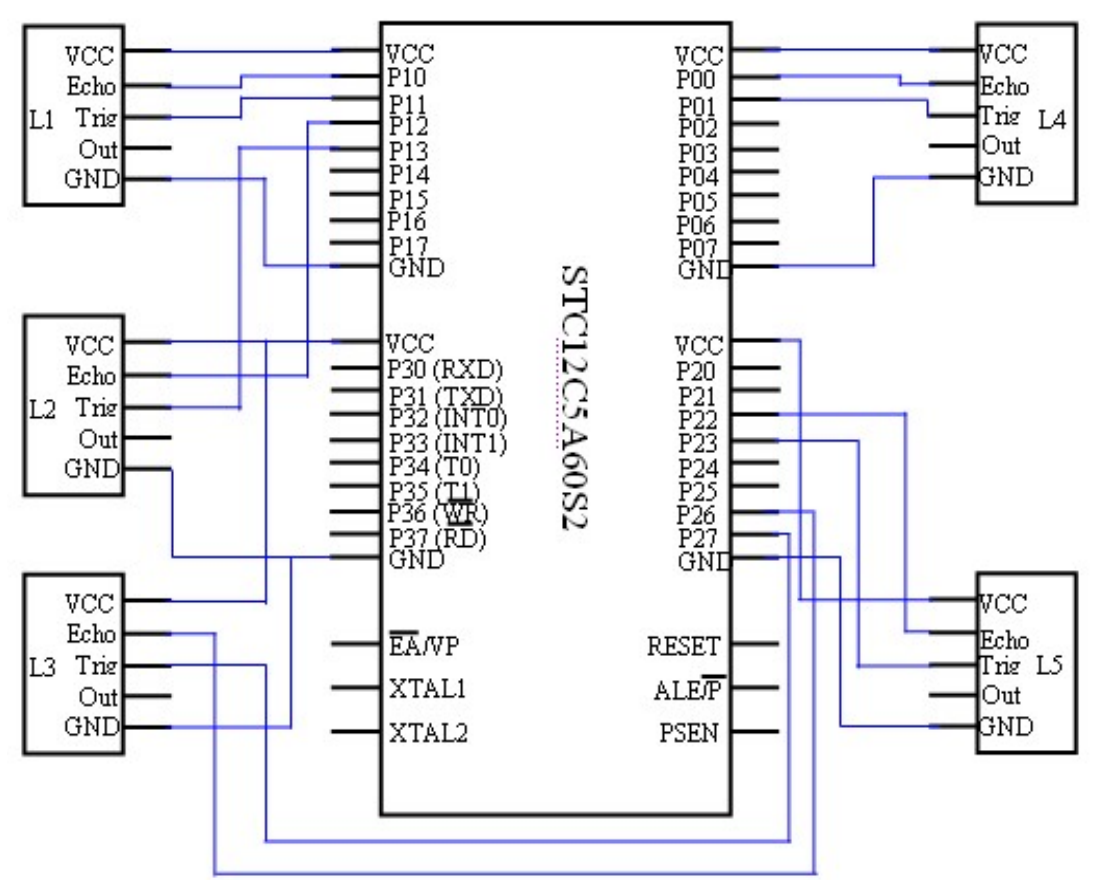

Fig. 5. Connection schematic view of ultrasonic sensors and single chip

\subsection{Installation Positions of Ultrasonic Sensors and Single Chips}

A mast was fixed on the center of tractor tail, whose length, width (which was parallel with crop row) and height were $5 \mathrm{~m}, 0.08 \mathrm{~m}$ and $0.05 \mathrm{~m}$ respectively. Sensors and single chips were mounted on the mast, whose installation schematic view is shown in Figure 6. Where $\mathrm{H}_{\mathrm{T}}$ is the tree height above the ground, $\mathrm{H}_{\mathrm{S}}$ is the height from ground to canopy skirt, $D_{R}$ is the crop row spacing, $D_{C}$ is the distance between sensors and center line of crop row, $D_{i}$ is the distance between sensor $i$ and the canopy foliage, $\mathrm{D}_{\mathrm{S}}$ is the sensor spacing. The height above the ground of sensors and the sensor spacing could be adjusted by the actual experimental objects. 


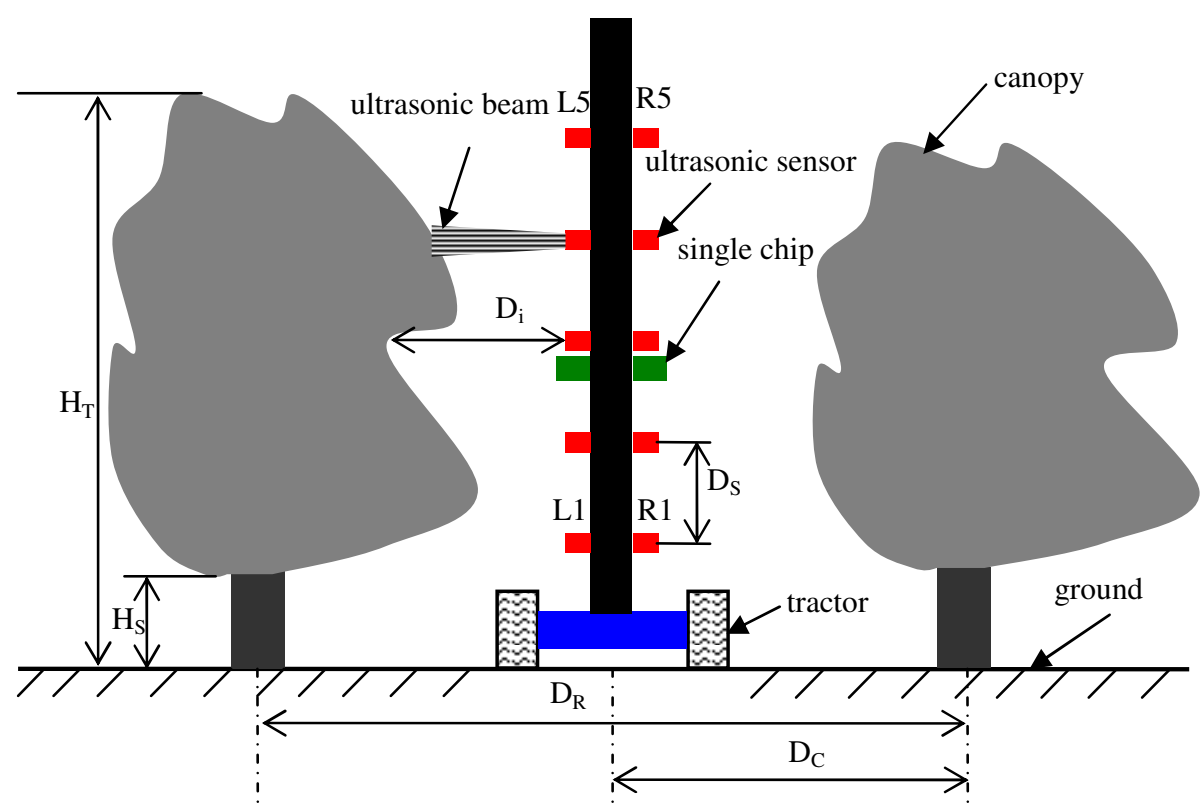

Fig. 6. Installation schematic view of ultrasonic sensors and single chips

\subsection{Design of Flow Control Mechanism}

Nozzle flows were changed with the change of canopy diameter values measured by sensors, so electro proportion control valve (EPCV) and electromagnetism valve (EV) were used to adjust the nozzle flows. Schematic view of flow control mechanism is shown in Figure 7. Electro proportion control valves and electromagnetism valves were controlled by single chip based on the canopy diameters detected by ultrasonic sensors. Pressure of pump outlet was reduced by proportional decompressing valve, and was maintained between 0 and $0.6 \mathrm{MPa}$ to ensure the normal application pressure needed by application equipment. The flow and pressure were measured by flow meter and pressure meter respectively.

\section{Software Design}

\subsection{System Interface Design}

Start interface of the whole system designed by VC software is shown in Figure 8 . Three systems could be accessed from the start interface, which were laboratory measurement system of canopy volume, orchard measurement system of canopy volume and variable rate spraying system based on canopy volume measurement.

The working screen capture of orchard measurement system of canopy volume is shown in Figure 9, where "parameters setup" area is used to set system working 
parameters, such as the distance between sensors and center line of crop row, sensor spacing and heights above ground of sensors. "Canopy diameter display" is used to display the canopy diameters detected by sensors, the crop number is also displayed in this area. "Tree shape display" area is used to display the tree shape vividly. The buttons on the bottom of the interface are used to start or stop the work of sensors and quit the system. "Start left series sensors" and "start right series sensors" in Figure 9 are grayer, which indicates that the left and right series sensors are working. The experiment details were introduced by Kaiqun $\mathrm{Hu}[17]$.

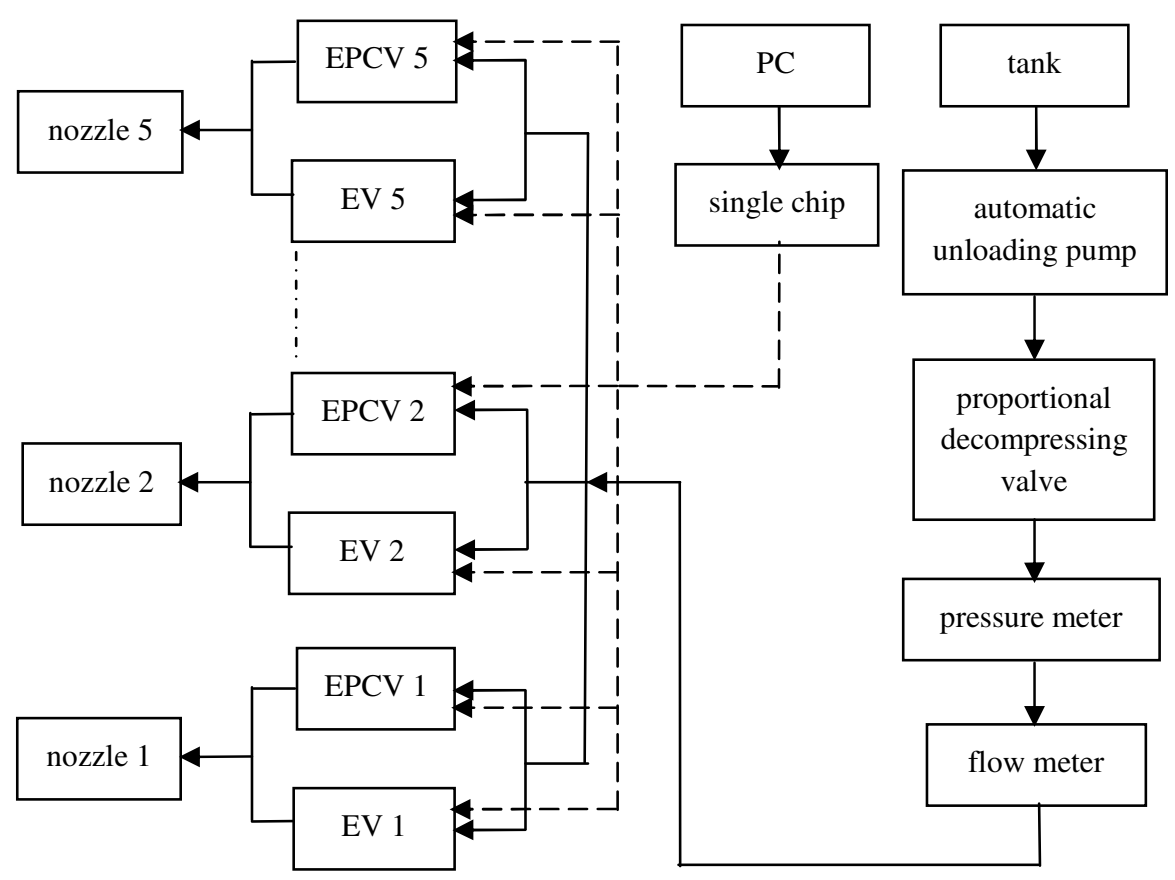

Fig. 7. Schematic view of flow control mechanism

The working screen capture of variable rate spraying system based on canopy volume measurement is shown in Figure 10, where "parameters setup" area is used to set system parameters, "crop parameter display" area is used to display the crop number, canopy volume of a single crop and canopy diameters detected by sensors. "Nozzle flow display" area is used to display the current nozzle flows. Buttons on the bottom left of the interface are used to start or stop spraying and quit the system. "Start left spraying" button in Figure 9 is grayer, which indicates that only the left spraying unit is started, so only the crop parameters and nozzle flows of left spraying unit are displayed in Figure 10. 


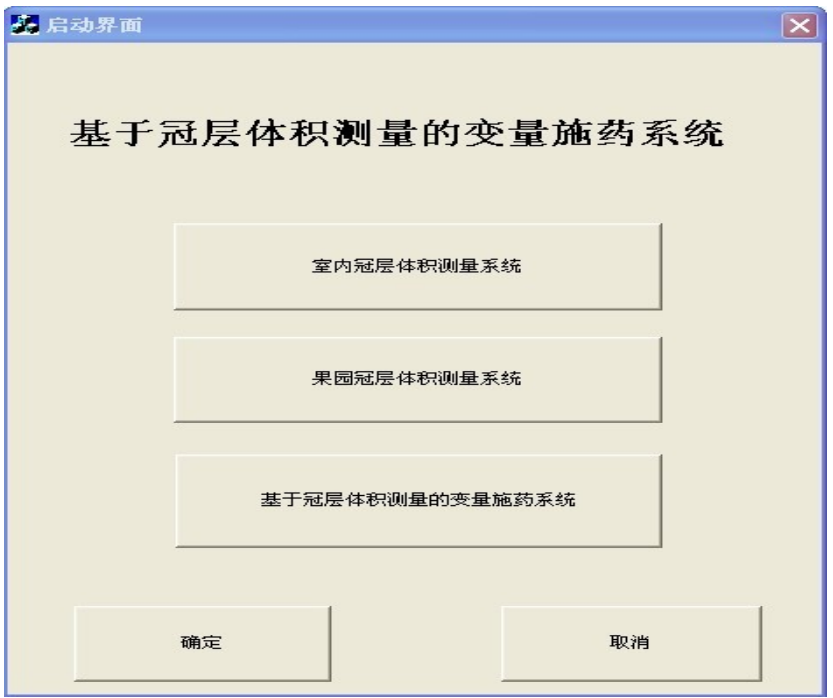

Fig. 8. Start interface of the whole system

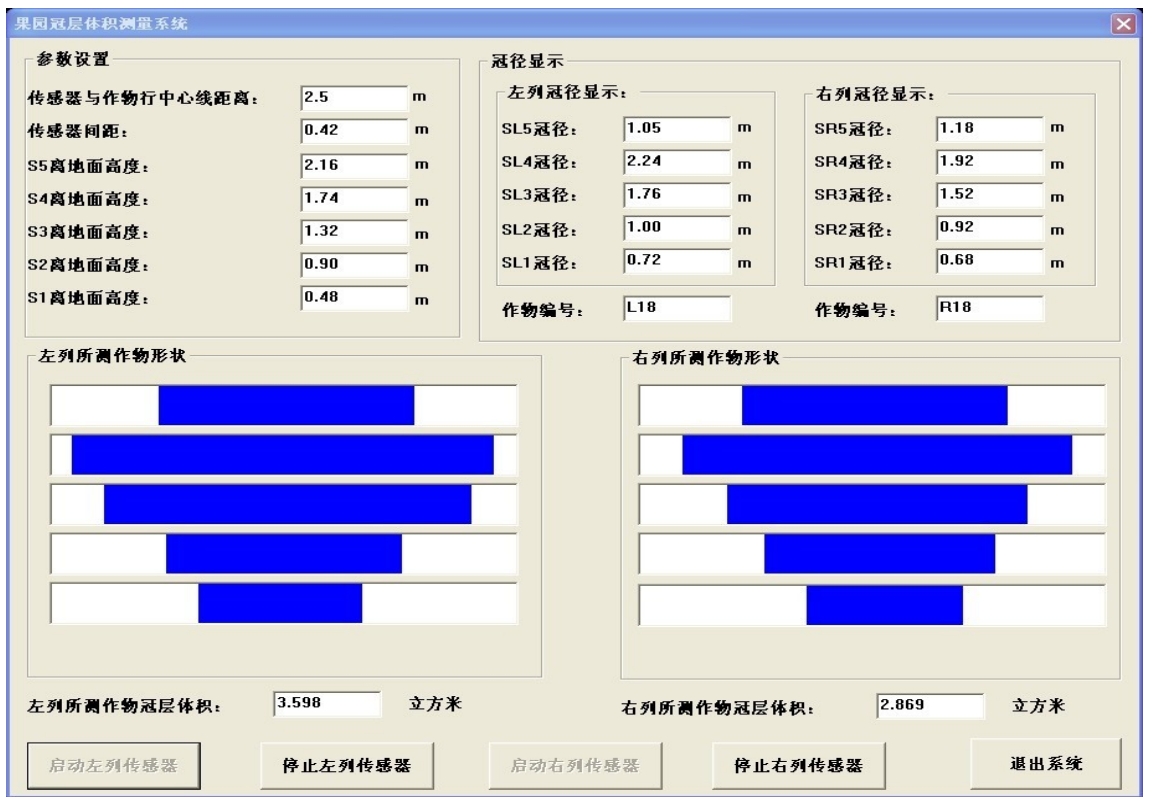

Fig. 9. The working screen capture of orchard measurement system of canopy volume 


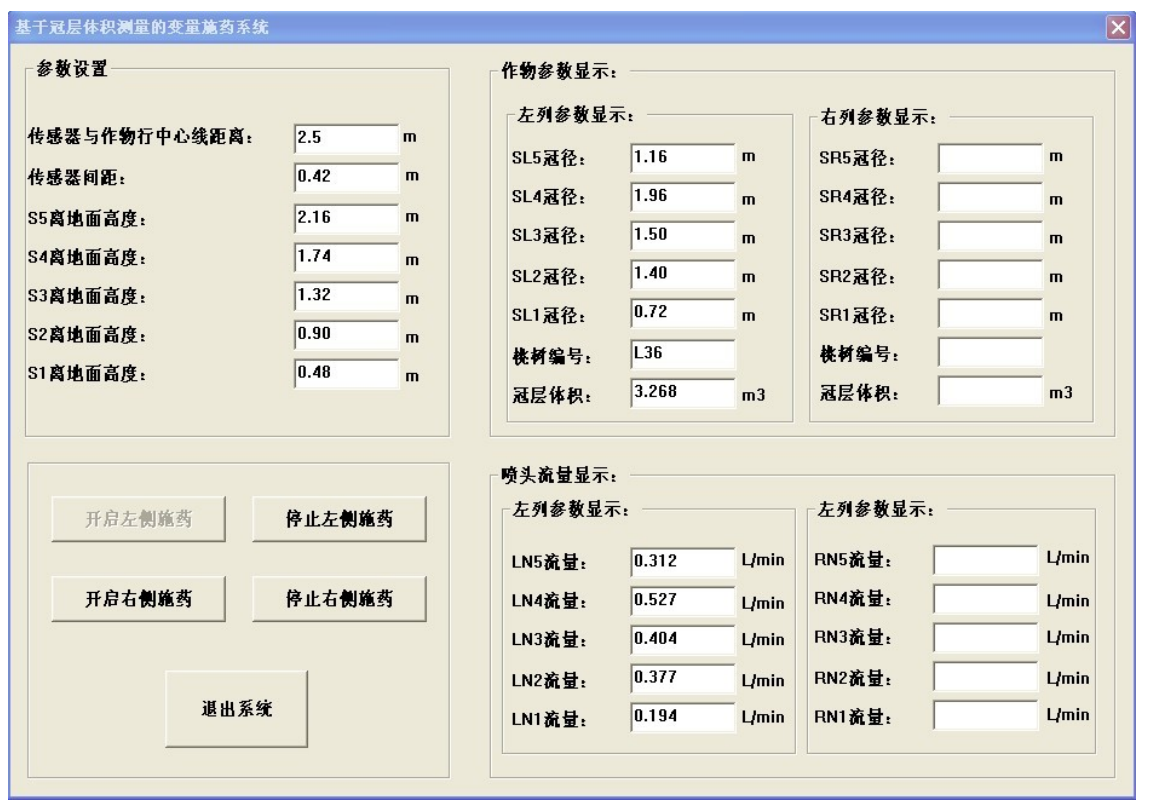

Fig. 10. The working screen capture of variable rate spraying system based on canopy volume measurement

\subsection{Flow Chart Design}

The control flow chart of single chip to ultrasonic sensors is shown in Figure 11. Where the single chip is started and initialized first, and then waits for instructions from host computer. The single chip controls ultrasonic sensors by instructions of host computer, and also sends the measured data to computer by RS232 serial port for further data processing.

Taking one ultrasonic sensor as an example, the work flow chart of sensor is shown in Figure 12. Where $t$ is the calculagraph reading after completing sampling, the subscript represents sampling times, buffer $\mathrm{T}$ is used to store the lesser calculagraph reading of two adjacent samplings. At last, the minimum value was gained, and the minimum distance between sensors and canopy foliage was calculated. 


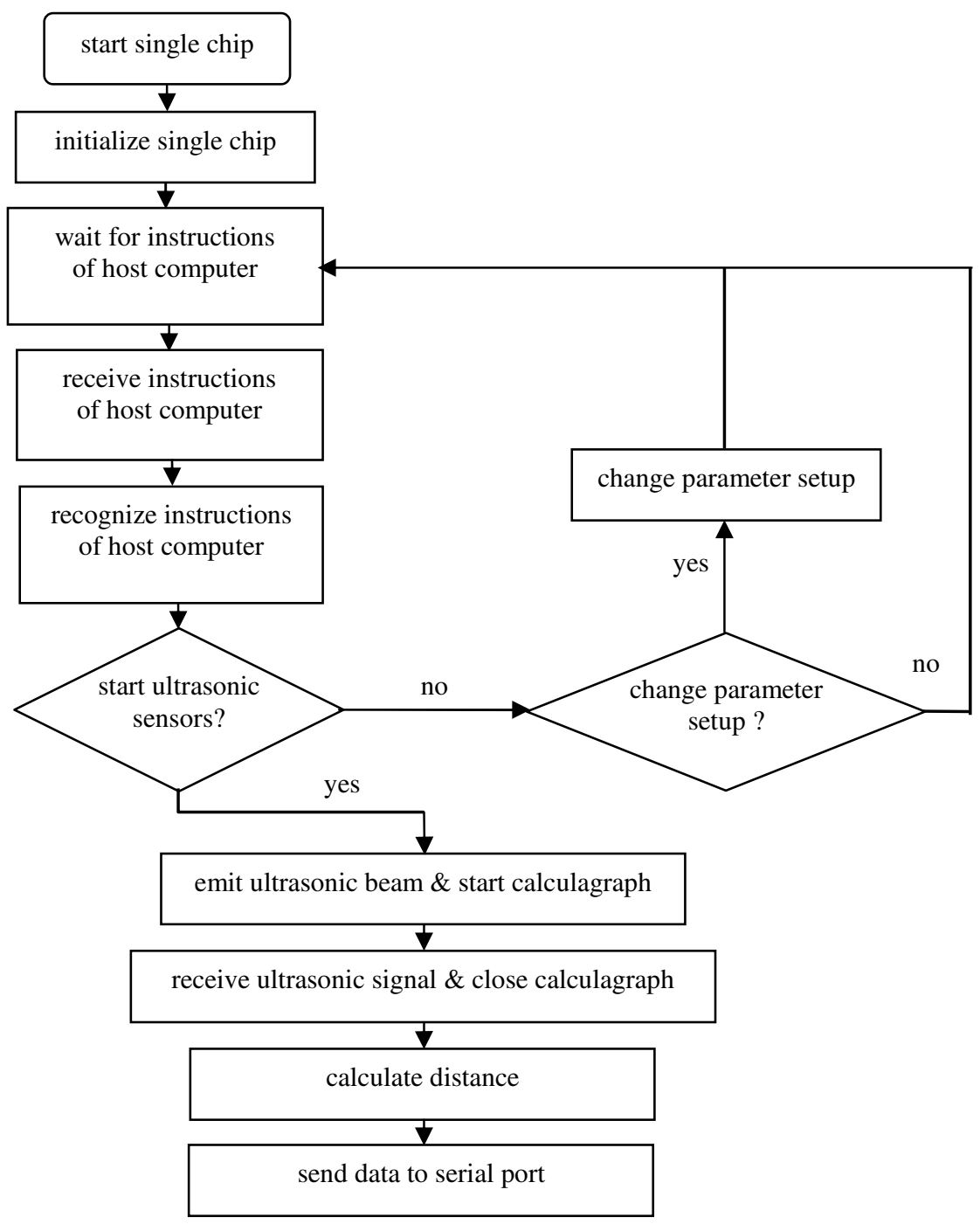

Fig. 11. The control flow chart of single chip to ultrasonic sensors 


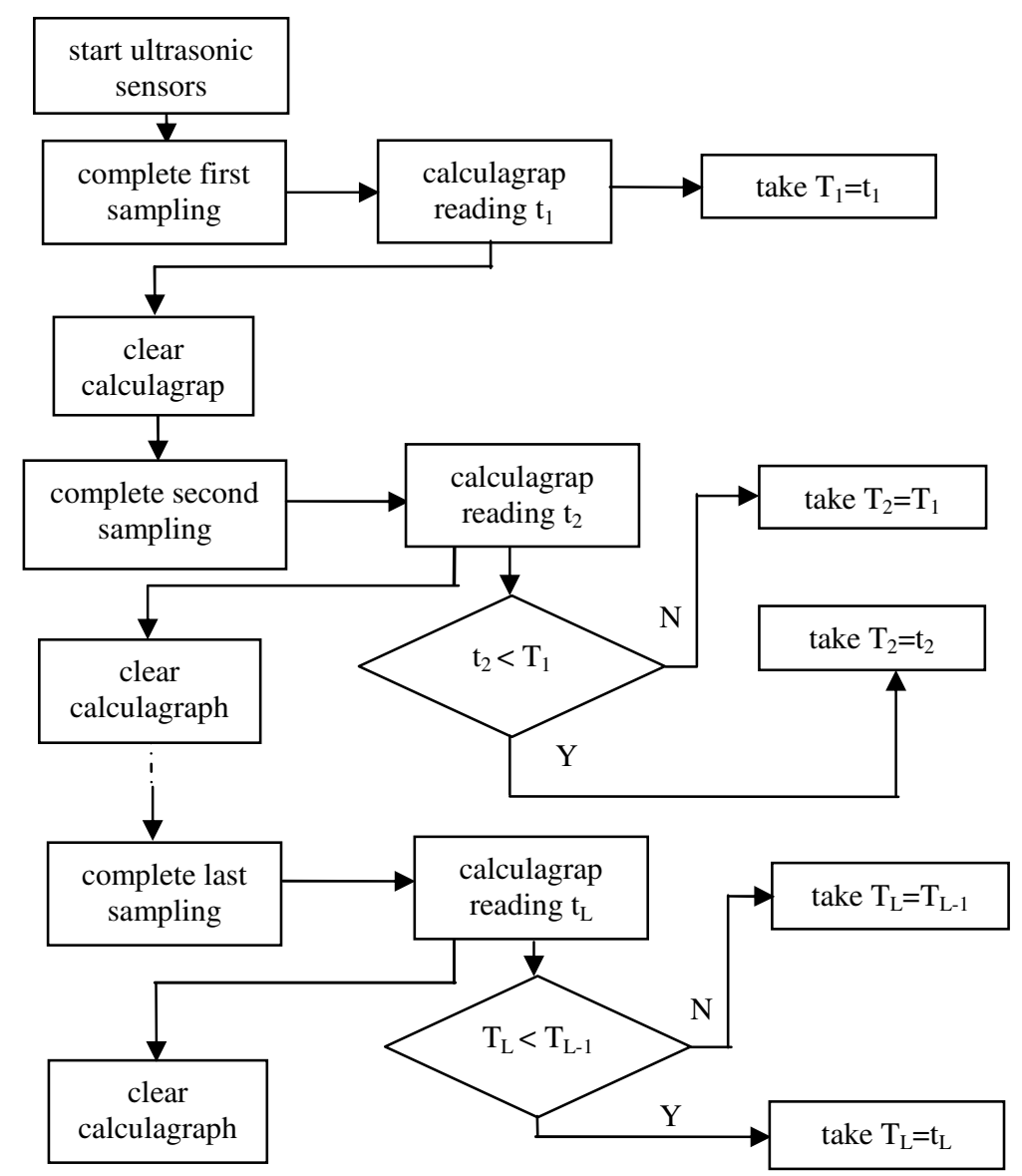

Fig. 12. The work flow chart of ultrasonic sensor

\section{Conclusion and Discussion}

A variable rate spraying system based on canopy volume measurement was presented and developed, which included PC, single chip, ultrasonic sensors, flow control mechanism and nozzles. Hardware and soft ware designs were introduced in this research. Hardware design mainly included choice of hardware, connections of hardware and installation of hardware. Software design mainly included system interface design and flow chart design. Canopy volumes could be measured by this system, the measurement results could be displayed in system interface vividly, and the system control could be implemented from the system interface.

The system realized the automatic measurement of canopy volumes, but more experiments should be done to determine the accuracy and applicability of the system, affection of weather conditions such as wind velocity, wind direction on the system, and the canopy volume measurement time of the system should be analyzed to confirm whether the time delay is allowed in the whole variable rate spraying system. 
Acknowledgements. We wish to thank Zhang Jianhua for their technical assistance. The work was funded by the National Key Technology R\&D Program of China (2007BAD89B04) and the National High-tech R\&D Program of China (2008AA100905).

\section{References}

1. The MT-9000 Automatic Rate Control. GPS and PC Compatible for Variable Rate Application, http: / /www.micro-trak.com/2004Catalog/

2. Qiu, B.J., Li, H.F., Wu, C.D., et al.: One variable-rate spraying equipment and its key technology. Jiangsu University: Natural Science Edition 25(2), 97-100 (2004)

3. Li, H.F., Qiu, B.J., Liu, B.L., et al.: Study on the control of variable-rate spraying in precision agriculture. Chinese Agricultural Mechanization 3, 25-27 (2004)

4. Shi, W.P., Wang, X., Wang, X.Z., et al.: Variable rate spraying technology on the basis of GPS and GIS. Journal of Agricultural Mechanization Research 2, 19-21 (2007)

5. Durand-Wayland Inc., Smart spray operator's manual. LaGrange, GA (1998)

6. Schumann, A.W., Zaman, Q.U.: Computers and Electronics in Agriculture 47, 25 (2005)

7. Ritchie, J.C., Evans, D.L., Jacobs, D., Everitt, J.H., Weltz, M.: Transactions of ASAE 36, 1235 (1993)

8. Nilsson, M.: Remote Sensing and Environment 56, 1 (1996)

9. Tian, L.: Sensor-based precision chemical application systems. World Congress of Computers in Agriculture and Nature Resources, 279-289 (2002)

10. Tian, L.: Development of a sensor-based precision herbicide application system. Computers and Electronics in Agriculture 36, 133-149 (2002)

11. Tian, L., Reid, J.R., Hummel, J.W.: Development of precision sprayer for site-specific weed management. Transaction of ASAE 42(4), 893-900 (1999)

12. Rehfeld, F. L.: Fluid motor metering device:USA, 4832071[P] (December 28, 1987)

13. Womac, A.R., Valcore, D.L., Maynard, R.: Variable-concentration direct injection from fixed-ratio diluent-driven pumps. Transactions of the ASAE 45(6), 1721-1728 (2002)

14. Guo, Y.B., He, X.K., Song, J.L., et al.: Application of static state blender in auto mix pesticide equipment. Journal of Agricultural Mechanization Research 2, 147-149 (2008)

15. Zhou, H.Y., Yang, X.J., Yan, H.R., et al.: Variable ratio spraying pesticide injection system. In: China Agricultural Machinery Association 2008 Annual Conference Proceedings (2008)

16. Hu, K.Q., Qi, L.J., Fu, Z.T.: Research on the Influence Factors of Ultrasonic Measurement System of Tree Canopy Volume. Sensor Letters 9, 1220-1224 (2011)

17. Hu, K.Q.: Design and Research of Variable-rate Spraying System Based on Canopy Volume Measurement, doctoral dissertation of China Agriculture University (2011) 